\title{
Comparison of Risk Factor Profile and Angiographic Pattern Among Pre-Menopausal and Post-Menopausal Women Presenting with Angina: Results from a Prospective Single Center Observational Study
}

Arvind Kandoria, Rajeev Bhardwaj, Kunal Mahajan*, Prakash C Negi, Neeraj Ganju, Sanjeev Asotra, Rajeev Merwaha, Davinder Pal Singh, Rajesh Sharma, Vivek Rana, Prince Kumar Paul, and Sanjay Rathore

Department of Cardiology, Indira Gandhi Medical College, India

\begin{abstract}
Background: Coronary artery disease (CAD) has become the major killer in women. The exact mechanism of postmenopausal increase in CAD is still under research. Limited data exists on the comparison of risk factor profiles
\end{abstract} and angiographic disease patterns in premenopausal and postmenopausal women.

Methods: This prospective study included a total of 674 consecutive female patients who underwent coronary angiogram for suspected ischemic heart disease over a period of 2 years from March 2015. Detailed risk factor profiles and angiographic patterns of disease were recorded and analyzed using EPIINFO statistical software.

Results: Out of total 674 patients, $137(20.3 \%)$ were in the premenopausal group with mean age of $(42.05 \pm$ $4.40)$ years, and $537(79.7 \%)$ in the postmenopausal group with mean age of $(59.05 \pm 8.01)$ years. Premenopausal women were more likely to be obese $(57.7 \%$ vs $46.9 \%, p=0.0)$, hypothyroid $(23.4 \%$ vs $10.2 \%, p<0.0001)$ and more likely to have a positive family history of premature CAD $(38.7 \%$ vs $6.3 \%, p<0.0001)$. On the other hand, postmenopausal women were more likely to be diabetic $(22.5 \%$ vs $13.1 \%, p=0.008)$, hypertensive $(74.3 \%$ vs $51.8 \%$, $p<0.0001)$, smokers $(29.4 \%$ vs $19.7 \%, p=0.01)$ and had $\geq 3$ risk factors more frequently $(42.1 \%$ vs $30.7 \%, p=0.009)$. Atypical chest pain was more common as presenting diagnosis among premenopausal women $(23.4 \% \mathrm{vs} 10.2 \%$, $p<0.0001)$. They were also more likely to have positive exercise stress test $(62.1 \%$ vs $38.3 \%, p<0.0001)$ and normal coronary angiogram $(59.9 \%$ vs $32 \%, p<0.0002)$ with endothelial dysfunction $(84.7 \%$ vs $66.8 \%, p<0.0001)$ than post-menopausal women. Post-menopausal women had greater burden of obstructive CAD characterized by more prevalent multivessel disease in the form of double vessel $(17.5 \%$ vs $8 \%, p=0.06)$ and triple vessel disease $(20.5 \%$ vs $5.8 \%, p<0.0002)$.

Conclusion: There is a distinct difference between the risk factor profile and angiographic disease pattern among women according to the status of menopause. Recognition of these differences would help in better understanding of relationship of menopause to development of CAD.

Keywords: Menopause; Coronary artery disease; Risk factors; Coronary angiography

\section{Background}

Cardiovascular disease (CVD) is the number one killer of women in both the developed and developing countries. Previously thought as a disease primarily affecting men, it is now estimated that 1 of 3 women dies of CVD in the United States, compared with 1 in 25 women who dies of breast cancer. About half of these deaths (1 in 6) are caused by coronary artery disease [1]. It has been long recognized universally that coronary artery disease (CAD) first presents approximately 10 years later among women than among men, and usually after menopause [2]. Despite this delayed onset, mortality from CAD among women is increasing more rapidly in comparison to men [3]. Alarmingly there is a substantially more prominent increase in coronary deaths among young premenopausal women compared to the men of same age [4,5]. This is despite the observation that the incidence and extent of CVD among premenopausal women is lower than among men of comparable age, even after correction for various risk factors [6]. It is still unclear how menopause affects coronary artery disease. There are hardly any studies which have systematically recorded the risk factor profiles and compared them with the angiographic pattern of disease, according to the status of menopause. The aim of this study was to study the differences in risk factor profile and coronary angiographic pattern of disease among pre- and post-menopausal women. Such studies are expected to bridge the knowledge gap in understanding the effect of menopause on development of CAD.

\section{Methods}

This prospective study was done at the Department of Cardiology, in a tertiary care hospital in Shimla, Himachal Pradesh, India. All the female patients who presented to the department of cardiology over a two years period from March 2015 with clinical suspicion of coronary ischemia, based on the presence of angina with or without an abnormal stress test, were considered for participation in the study. Patients with acute coronary syndrome (ACS) were also included. ACS patients were then categorized into ST segment elevation myocardial infarction (STEMI) or non-ST segment elevation myocardial infarction/unstable angina (NSTEMI/UA). STEMI was diagnosed if ECG showed evidence of ST segment elevation in $\geq 2$ contiguous leads. Those without ST segment elevation were labelled as NSTEMI/UA based on the presence

*Corresponding author: Kunal Mahajan, Department of Cardiology, Indira Gandh Medical College, India, Tel: +918628864820; E-mail: kunalmahajan442@gmail.com

Received March 15, 2017; Accepted March 30, 2017; Published March 31, 2017

Citation: Kandoria A, Bhardwaj R, Mahajan K, Negi PC, Ganju N, et al. (2017) Comparison of Risk Factor Profile and Angiographic Pattern Among PreMenopausal and Post-Menopausal Women Presenting with Angina: Results from a Prospective Single Center Observational Study. J Cardiovasc Dis Diagn 5: 266. doi: 10.4172/2329-9517.1000266

Copyright: (c 2017 Kandoria A, et al. This is an open-access article distributed under the terms of the Creative Commons Attribution License, which permits unrestricted use, distribution, and reproduction in any medium, provided the original author and source are credited. 
of elevated cardiac enzymes. Patients with valvular heart disease, cardiomyopathy, pulmonary artery hypertension, congenital heart disease, renal failure and pregnancy were excluded from the study. Those refusing to give consent were also excluded.

All the eligible patients were subjected to detailed medical history for assessing nature and duration of chest pain, menstrual status and risk factor profile. Examination was carried out to examine the pulse, blood pressure and body mass index (BMI) using appropriate and validated tools.

The clinical presentation of patients was categorized as STEMI, NSTEMI/UA, typical chest pain and atypical chest pain. Chest pain was labelled as typical if it met all three of the following criteria: (1) retrosternal chest discomfort described as pressure, tightness or heaviness with duration no more than 10 minutes in most of the cases (2) provoked by exertion or emotional stress and (3) relieved by rest and/or nitrates. Atypical angina was defined as meeting 2 of the above characteristics. International cut off points of the body mass index (BMI) for Asian populations were used to assess overweight (BMI $\geq 23 \mathrm{~kg} / \mathrm{m}^{2}$ to $\left.24.99 \mathrm{~kg} / \mathrm{m}^{2}\right)$ and obesity $\left(\geq 25 \mathrm{~kg} / \mathrm{m}^{2}\right)$. Smokers were defined as all those patients who regularly smoked an average of one or more cigarettes a day for at least 1 year. Patients on oral hypoglycemic agents or Insulin and/or those having fasting blood sugar $\geq 126 \mathrm{~g} / \mathrm{dl}$ were regarded as having diabetes mellitus. Hypertension was diagnosed if blood pressure $>140 / 90 \mathrm{mmHg}$ was recorded twice or in those on antihypertensive drugs. A diagnosis of dyslipidemia was made if total Cholesterol was $>160 \mathrm{mg} / \mathrm{dl}$, triglycerides $>150 \mathrm{mg} / \mathrm{dl}$, low density lipoprotein (LDL) cholesterol $>130 \mathrm{mg} / \mathrm{dl}$ and high density lipoprotein (HDL) cholesterol was $<50 \mathrm{mg} / \mathrm{dl}$. Women with history of ischemic heart disease in first degree male relatives of less than 55 years or in female relatives less than 65 years were regarded as having family history of premature coronary artery disease. Menopause was considered to be present when there was no history of menstrual periods for the last one year. Modified Minnesota leisure time questionnaire [7] was used to define the physical activity of patient as heavy, medium and light/ sedentary.

Baseline transthoracic echocardiographic examination was done in all patients to assess regional wall motion abnormalities and left ventricular function, using American Society of Echocardiography guidelines $[8,9]$. Coronary angiography was performed with Siemens Artis Zee Cath Lab Equipment through standard radial or femoral artery approach. Angiographic data was analyzed by using quantitative coronary analysis software by two different cardiologists independently and any discrepancies in analysis were settled at the same time. Obstructive CAD was diagnosed if lesion causing luminal narrowing $\geq 50 \%$ was observed in one or more epicardial coronary arteries. It was further classified into single vessel disease (SVD), double vessel disease (DVD) and triple vessel disease(TVD). Non-obstructive CAD was defined if only lumen irregularities were seen and/ or if stenosis was seen causing $<50 \%$ luminal narrowing. Normal epicardial coronaries were defined as having no luminal irregularities and luminal stenosis. In patients with normal epicardial coronaries, endothelial dysfunction was diagnosed by corrected TIMI (Thrombolysis in Myocardial Infarction) frame count $>21$ at a frame rate of $30 \mathrm{~mm} / \mathrm{sec}$. The presence of a myocardial bridge was defined by $\geq 10 \%$ systolic compression of the epicardial coronary artery during the cardiac cycle.

\section{Statistical Analysis}

Continuous variables are presented in means \pm standard deviation. Categorical variables are presented as proportions. Differences between pre- and postmenopausal women were compared using the student t-test for continuous variables and the chi-square test for categorical variables. Two-tailed significance at $<0.05$ was taken as statistically significant. All analyses were performed using EPI INFO version 3.4.3 (Center for disease control and prevention, United States).

\section{Results}

A total of 798 female patients underwent coronary angiography at our center over a period of 2 years since March 2015. 124 patients were excluded from the final study cohort as per pre-defined exclusion criteria. The remaining 674 patients were taken for the final analysis. The patients were divided into 2 groups, based on the status of menopause. The first group (Premenopausal) consisted of $137(20.3 \%)$ patients who were yet to attain menopause. The remaining $537(79.7 \%)$ postmenopausal women formed the second group (Figure 1). The differences between the baseline characteristics and risk factors among the two groups are detailed in Table 1. The mean age in premenopausal group was $42.05 \pm 4.40$ years, which was around 17 years younger than the mean age of postmenopausal women $(59.05 \pm 8.01)$.

\section{Distribution of risk factor profile}

In comparison to postmenopausal women, premenopausal women were more likely to be obese ( $57.7 \%$ vs $46.9 \%, \mathrm{p}=0.01$ ) and hypothyroid $(23.4 \%$ vs $10.2 \%, \mathrm{p}<0.0001)$. Premenopausal women were also more likely to have a positive family history of premature CAD $(38.7 \%$ vs $6.3 \%, \mathrm{p}<0.0001)$ and a LDL Cholesterol level $>100 \mathrm{mg} / \mathrm{dl}(68.6 \% \%$ vs $58.7 \%, \mathrm{p}<0.0001)$, than the postmenopausal women.

In contrast, the postmenopausal women were more likely to be smokers $(29.4 \%$ vs $19.7 \%, \mathrm{p}=0.01)$, diabetic $(22.5 \%$ vs $13.1 \%, \mathrm{p}=0.008)$ and hypertensive $(74.3 \%$ vs $51.8 \%, \mathrm{p}<0.0001)$ than the premenopausal women. They were also more likely to have 3 or more risk factors for CAD ( $42.1 \%$ vs $30.7 \%, \mathrm{p}=0.009)$ and a serum HDL Cholesterol level of less than $40 \mathrm{mg} / \mathrm{dl}$ ( $43.9 \%$ vs $28.5 \%$, $\mathrm{p}=0.0005)$.

\section{Differences in presentation pattern}

The main presentation diagnosis in both the groups was chronic stable angina. However, a significantly higher number of premenopausal women presented with atypical chest pain than postmenopausal women $(23.4 \%$ vs $10.2 \%, \mathrm{p}<0.0001)$. STEMI as the presenting diagnosis was more commonly seen in postmenopausal women $(7.6 \%$ vs $2.9 \%$, $\mathrm{p}<0.0001)$. Significantly higher proportion of postmenopausal women presented with LV systolic dysfunction in comparison to premenopausal women. Although a significantly high number of postmenopausal women did not undergo exercise stress test $(60.6 \%$ vs $31.9 \%, \mathrm{p}<0.0001)$,

\section{- Premenopausal Postmenopausal}

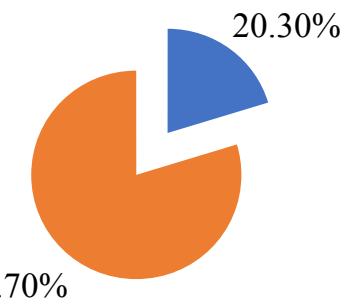

Figure 1: Distribution of study population according to status of menopause. 
Citation: Kandoria A, Bhardwaj R, Mahajan K, Negi PC, Ganju N, et al. (2017) Comparison of Risk Factor Profile and Angiographic Pattern Among Pre-Menopausal and Post-Menopausal Women Presenting with Angina: Results from a Prospective Single Center Observational Study. J Cardiovasc Dis Diagn 5: 266. doi: 10.4172/2329-9517.1000266

Page 3 of 5

positive result was seen more frequently in premenopausal women $(62.1 \%$ vs $38.3 \%, \mathrm{p}<0.0001)$.

\section{Differences in coronary angiographic profile}

The differences in coronary angiographic profile based on menopausal status are depicted in Table 2. Normal epicardial coronary arteries were seen in a significantly higher number of premenopausal women $(59.9 \%$ vs $32 \%, \mathrm{p}<0.0002)$. In those with normal coronary angiogram, endothelial dysfunction was also observed more commonly in premenopausal women $(84.7 \%$ vs $66.8 \%, \mathrm{p}<0.0001)$. The proportion of women with SVD was not statistically different between the two groups $(23.3 \%$ vs $24.1 \%, \mathrm{p}=0.84)$. On the other hand, DVD $(17.5 \%$ vs $8 \%, \mathrm{p}=0.06)$ and TVD $(20.5 \%$ vs $5.8 \%, \mathrm{p}<0.0002)$ were more prevalent in the postmenopausal women (Figure 2).

Left main coronary artery (LMCA) was more prevalent among postmenopausal women $(6.2 \%$ vs $1.5 \%, \mathrm{p}=0.01)$. While left anterior descending (LAD) artery was the most commonly involved artery in postmenopausal women, it was Right coronary artery (RCA), which was the more frequently affected in premenopausal women (Figure 3). No calcific lesions were seen in premenopausal women in comparison to $16 \%$ of postmenopausal women having calcific lesions on angiogram. Spontaneous dissections were more common among premenopausal women $(9.5 \%$ vs $0.9 \%, \mathrm{p}<0.0001)$. Myocardial bridge was seen with equal frequency in the two groups ( $8 \%$ vs $8.2 \%$ ).

\section{Discussion}

It still remains unclear how menopause is related to atherosclerosis and CAD $[10,11]$. Conflicting data exists regarding the protective role of Oestrogen against coronary artery disease. Menopause occurs at an early age in Indian women than their western counterparts [12]. Since CAD has become the major cause of death in women [13], It therefore,

\begin{tabular}{|c|c|c|c|}
\hline & Premenopausal & Postmenopausal & $p$-value \\
\hline Number (Total=674) & $137(20.3 \%)$ & $537(79.7 \%)$ & \\
\hline Mean Age (years) & $42.05 \pm 4.40$ & $59.05 \pm 8.01$ & 0.0001 \\
\hline$\geq 3$ Risk Factors & $42(30.7 \%)$ & $226(42.1 \%)$ & 0.009 \\
\hline Sedentary Lifestyle & $89(65 \%)$ & $318(59.2 \%)$ & 0.11 \\
\hline Obesity/Overweight (BMI $\geq 23 \mathrm{~kg} / \mathrm{m}^{2}$ ) & $79(57.7 \%)$ & $252(46.9 \%)$ & 0.01 \\
\hline Diabetes Mellitus & $18(13.1 \%)$ & $121(22.5 \%)$ & 0.008 \\
\hline Hypertension & $71(51.8 \%)$ & $399(74.3 \%)$ & $<0.0001$ \\
\hline \multicolumn{4}{|l|}{ Dyslipidemia } \\
\hline LDL $>100$ & $94(68.6 \%)$ & $272(50.7 \%)$ & $<0.0001$ \\
\hline $\mathrm{HDL}<40$ & $39(28.5 \%)$ & $236(43.9 \%)$ & 0.0005 \\
\hline Smoking & $27(19.7 \%)$ & $158(29.4 \%)$ & 0.01 \\
\hline Family history of premature CAD & $53(38.7 \%)$ & $34(6.3 \%)$ & $<0.0001$ \\
\hline Hypothyroidism & $32(23.4 \%)$ & $55(10.2 \%)$ & $<0.0001$ \\
\hline \multicolumn{4}{|l|}{ Presentation Diagnosis } \\
\hline a) STEMI & $4(2.9 \%)$ & $41(7.6 \%)$ & \\
\hline b) NSTEMI/UA & $14(10.2 \%)$ & 37 (6.9\%) & 0.0001 \\
\hline c) Chronic Stable Angina & $75(54.7 \%)$ & $356(66.3 \%)$ & \\
\hline d) Atypical Angina & $44(32.1 \%)$ & $103(19.2 \%)$ & \\
\hline Exercise stress test in non-ACS Patients & 119 & 459 & \\
\hline Positive & $74(62.1 \%)$ & $176(38.3 \%)$ & \\
\hline Not Done & $38(31.9 \%)$ & $278(60.6 \%)$ & $<0.0001$ \\
\hline Inconclusive & $7(6 \%)$ & $5(1.1 \%)$ & \\
\hline LV Dysfunction & $13(9.5 \%)$ & $90(16.8 \%)$ & 0.02 \\
\hline
\end{tabular}

Table 1: Baseline characteristics and risk factors among the study population.

\begin{tabular}{|l|c|c|}
\hline & Pre menopausal N=137 & Post menopausal N= 537 \\
\hline Normal Coronary Arteries & $82(59.9 \%)$ & $172(32 \%)$ \\
\hline $\begin{array}{l}\text { Endothelial dysfunction in absence of obstructive } \\
\text { lesions }\end{array}$ & $72(84.7 \%)$ & $139(66.8 \%)$ \\
\hline Nonobstructive Disease & $3(2.2 \%)$ & $36(6.7 \%)$ \\
\hline Number of vessels SVD & $33(24.1 \%)$ & $125(23.3 \%)$ \\
\hline DVD & $11(8 \%)$ & 9.0002 \\
\hline TVD & $8(5.8 \%)$ & $110(20.5 \%)$ \\
\hline Left Main Coronary Artery & $2(1.5 \%)$ & $33(6.2 \%)$ \\
\hline Calcification & 0 & 0.0001 \\
\hline Dissection & $13(9.5 \%)$ & $86(16 \%)$ \\
\hline Myocardial Bridge & $11(8 \%)$ & $5(0.9 \%)$ \\
\hline
\end{tabular}

Table 2: Differences in Coronary angiographic profile of the study groups. 


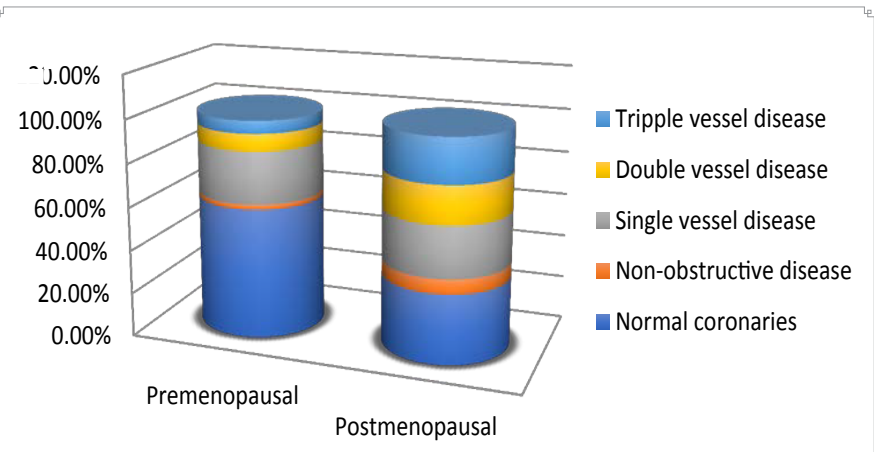

Figure 2: Angiographic distribution among study population based on the number of vessels involved.

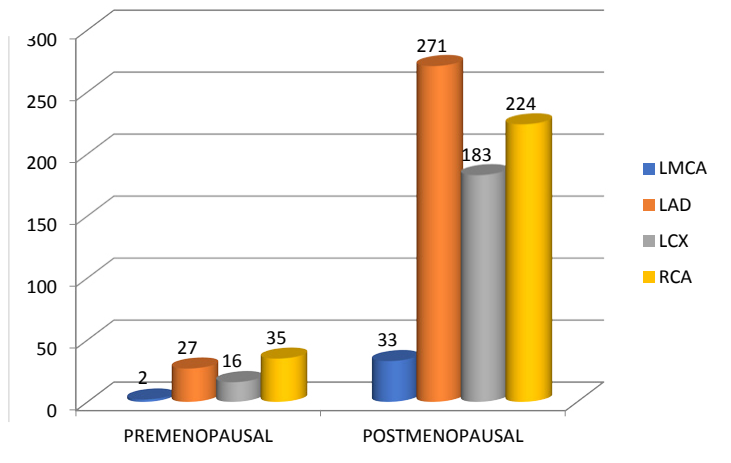

Figure 3: Angiographic pattern of coronary artery involvement among the study groups.

becomes imperative to understand the implications of early menopause in Indian women in causation of CAD.

The current study has 5 main findings. First, the premenopausal women present more commonly with atypical chest pain. Second, they are more likely to be obese with positive family history of premature CAD. But overall, the risk burden of CAD is lesser in them as compared to postmenopausal women. Third, exercise stress test is often underused in women as a diagnostic test before coronary angiogram, more so in postmenopausal women. A positive result is seen more commonly in premenopausal women despite greater prevalence of normal coronary angiogram in them. Fourth, the prevalence of normal coronary angiogram and endothelial dysfunction is more commonly observed in premenopausal women. Fifth, whilst SVD is the most common mode of presentation of CAD in premenopausal women, it is the multivessel involvement (DVD and TVD) that predominates in postmenopausal women.

The similar pattern of increasing risk of CAD after menopause has been documented in previous studies [14-17].

It is well recognized that women especially young women with CAD present more commonly with atypical symptoms [18,19]. Almost one-fifth of women in the present study presented with atypical chest pain, more commonly the premenopausal women.

The prevalence of CAD increases with age in both men and women. This is in part because of increase in the prevalence of cardiovascular risk factors with age. Prior studies have documented an increase in CAD risk factors in postmenopausal women [20,21]. The similar results were obtained in the present study. Postmenopausal women had higher prevalence of diabetes, hypertension and smoking and majority of them had three or more risk factors in comparison to premenopausal women. Interestingly, premenopausal women had higher prevalence of obesity and LDL cholesterol $>100 \mathrm{mg} / \mathrm{dl}$. This reflects the effects of lifestyle changes in young females, thereby making them more prone to develop CAD. The postmenopausal women had a higher prevalence of a low HDL cholesterol $<40 \mathrm{mg} / \mathrm{dl}$. Low HDL cholesterol predicts CVD strongly in women. It is known that the risk of coronary events increases significantly in women with low levels of HDL cholesterol [22]. Thus, low HDL cholesterol levels along with an overall greater risk factor burden could be the contributing factors for increased prevalence of $\mathrm{CAD}$ in postmenopausal women in the present series.

Exercise stress test was performed in only half of the study population. Similar pattern of its underuse has been documented in a recent Indian study [23]. The main reasons for underuse included patients' inability to walk on treadmill and physician's inertia in advising a exercise stress test before coronary angiogram. This may be due to the fact that exercise stress test has a very limited accuracy in women especially because of the resting ST-T wave changes, lower ECG voltage and certain hormonal factors [24]. Its sensitivity and specificity for the diagnosis of obstructive CAD in women range from $31 \%$ to $71 \%$ and from $66 \%$ to $86 \%$, respectively. Nevertheless, a negative exercise stress test provides significant diagnostic value [24].

Around $44 \%$ of women undergoing coronary angiogram in the present study were found to have normal or non-obstructive epicardial coronary arteries. This is slightly lesser than the published studies which have reported that as many as $50 \%$ of women undergoing coronary angiography for suspected IHD are found to have normal or non-obstructive epicardial coronary arteries [25-27]. Atherosclerotic burden is greater in postmenopausal women than premenopausal women as understood from the higher prevalence of obstructive CAD especially DVD, TVD and left main coronary artery disease in postmenopausal group and that of normal epicardial coronaries in the premenopausal women. Previous angiographic studies in women have also documented a rise in DVD and TVD as the age advances [23,28]. Premenopausal women also had greater prevalence of endothelial dysfunction. This along with higher prevalence of a positive stress test suggests a higher prevalence of micro-vascular angina in premenopausal women [29]. This is important since data from the women's ischemia syndrome evaluation (WISE) study suggests that such patients are more likely to have recurrent hospital admissions, rapid progression to obstructive CAD and greater cardiovascular mortality and morbidity when compared to the general population [30].

\section{Limitations}

No study is without limitations, so is ours. First, since the data is observational, there are chances that the potential residual confounders persist. These may influence potential associations between menopausal status and disease pattern that we did not demonstrate. Second, this is a single center study. The characteristics of CAD patients vary with socio-demographic profiles, so caution must be employed while extrapolating this data to other populations. Third, we did not record the age of menopause and the type of menopause systematically in the study groups. This would have provided more information on the effect of menopause on the development of CAD. Fourth, lack of use of intravascular ultrasound, optical coherence tomography and fractional flow reserve might have influenced the anatomical and functional severity of coronary artery lesions. 
Citation: Kandoria A, Bhardwaj R, Mahajan K, Negi PC, Ganju N, et al. (2017) Comparison of Risk Factor Profile and Angiographic Pattern Among Pre-Menopausal and Post-Menopausal Women Presenting with Angina: Results from a Prospective Single Center Observational Study. J Cardiovasc Dis Diagn 5: 266. doi: 10.4172/2329-9517.1000266

\section{Conclusion}

The strength of the study lies in systematic recording of the risk factor profiles and their comparison with the angiographic pattern of disease after stratification according to the status of menopause. This makes the results of present study noteworthy.

The study reveals a distinct difference in the pattern of CAD between the premenopausal and postmenopausal women, with a greater incidence of atypical angina, positive exercise stress test and angiographically normal epicardial coronaries with endothelial dysfunction in the premenopausal women. These women are more likely to develop obstructive $\mathrm{CAD}$ in future, warranting aggressive lifestyle and risk factor modification. In contrast, postmenopausal women have higher risk factor burden and more atherosclerotic disease burden reflected by more multivessel disease. Aggressive evidence based management of already established disease and risk factors, would decrease the cardiovascular mortality and morbidity in them.

\section{Acknowledgement}

We would like to thank and acknowledge the contribution of Mr. Raminder Dhiman, Research Assistant, Department of Cardiology in helping us with the data collection and statistical analysis.

\section{Financial Support and Sponsorship None}

Conflict of Interest All authors have none to declare.

\section{References}

1. Mozaffarian D, Benjamin EJ, Go AS (2016) Heart disease and stroke statistics-2016 update: A report from the American Heart Association. Circulation. 135: 646.

2. Yusuf S, Hawken S, Ounpuu S, Dans T, Avezum A, et al. (2004) Effect of potentially modifiable risk factors associated with myocardial infarction in 52 countries (the INTERHEART study): Case-control study. Lancet 364: 937-952.

3. Gersh BJ, Sliwa K, Mayosi BM, Yusuf S (2010) Novel therapeutic concepts: The epidemic of cardiovascular disease in the developing world: Global implications. Eur Heart J 31: 642-648.

4. Ford ES, Capewell S (2007) Coronary heart disease mortality among young adults in the U.S. from 1980 through 2002: Concealed leveling of mortality rates. J Am Coll Cardiol 50: 2128-2132.

5. Vaccarino V, Parsons L, Every NR, Barron HV, Krumholz HM (1999) Sex-based differences in early mortality after myocardial infarction. National Registry of Myocardial Infarction 2 Participants. N Engl J Med 341: 217-225.

6. Piro M, Della Bona R, Abbate A, Biasucci LM, Crea F (2010) Sex-related differences in myocardial remodeling. J Am Coll Cardiol 55: 1057-1065.

7. Aadahl M, Kjaer M, Jørgensen T (2007) Perceived exertion of physical activity: Negative association with self-rated fitness. Scand J Public Health 35: 403-409.

8. Lang RM, Badano LP, Mor-Avi V, Afilalo J, Armstrong A, et al. (2015) Recommendations for cardiac chamber quantification by echocardiography in adults: An update from the American Society of Echocardiography and the European Association of Cardiovascular Imaging. Eur Heart J Cardiovasc Imaging 16: 233-270.

9. Marwick TH, Gillebert TC, Aurigemma G, Chirinos J, Derumeaux G, et al. (2015) Recommendations on the use of echocardiography in adult hypertension: $A$ report from the European Association of Cardiovascular Imaging (EACVI) and the American Society of Echocardiography (ASE). J Am Soc Echocardiogr 28: $727-754$

10. Atsma F, Bartelink ML, Grobbee DE, Van der Schouw YT (2006) Postmenopausal status and early menopause as independent risk factors for cardiovascular disease: A meta-analysis. Menopause 13: 265-279.

11. Barrett-Connor E (2013) Menopause, atherosclerosis, and coronary artery disease. Curr Opin Pharmacol 13: 186-191.

12. Singh M (2012) Early age of natural menopause in India, a biological marker for early preventive health programs. Climacteric 15: 581-586.
13. Celermajer DS, Chow CK, Marijon E, Anstey NM, Woo AS (2012) Cardiovascular disease in the developing world: Prevalences, patterns, and the potential of early disease detection. J Am Coll Cardiol 60: 1207-1216.

14. Tremollieres FA, Pouilles JM, Cauneille C, Ribot C (1999) Coronary heart disease risk factors and menopause: A study in 1684 French women. Atherosclerosis 142: 415-423

15. Tchernof A, Calles-Escandon J, Sites CK, Poehlman ET (1998) Menopause, central body fatness and insulin resistance. Effects of hormone replacement therapy. Coronary A disease 9: 503-511.

16. Dosi R, Bhatt N, Shah P, Patell R (2014) Cardiovascular disease and menopause $\mathrm{J}$ Clin Diagn Res 8: 62-64.

17. Soman B, Rahaman MA, Rajan R, Vijayaraghavan G (2016) Risk factor profile and disease pattern in premenopausal and postmenopausal Indian women presenting with acute coronary syndrome. J Clin Prev Cardiol 5: 78-83.

18. Bairey Merz CN, Shaw LJ, Reis SE, Bittner V, Kelsey SF (2006) Insights from the NHLBI-sponsored women's ischemia syndrome evaluation (WISE) study: Part II: Gender differences in presentation, diagnosis, and outcome with regard to gender-based pathophysiology of atherosclerosis and macrovascular and microvascular coronary disease. J Am Coll Cardiol 47: S21-S29.

19. Canto JG, Goldberg RJ, Hand MM (2007) Symptom presentation of women with acute coronary syndromes: Myth vs reality. Arch Intern Med 167: 2405.

20. Bulliyya G (2001) Risk of coronary heart disease in women after menopause. J Indian Med Assoc 99: 478-480,482.

21. Azizi F, Ainy E (2003) Coronary heart disease risk factors and menopause: A study in 1980 Tehranian women, the Tehran Lipid and Glucose Study. Climacteric 6: 330-336

22. Montazerifar F, Bolouri A, Mozaffar M, Karajibani M (2016) The prevalence of metabolic syndrome in coronary artery disease patients. Cardiol Res 7: 202208.

23. Ezhumalai B, Jayaraman B (2014) Angiographic prevalence and pattern of coronary artery disease in women. Indian heart j 66: 422-426.

24. Gulati M, Black HR, Shaw LJ, Arnsdorf MF, Bairey Merz CN (2005) The prognostic value of a nomogram for exercise capacity in women. $N$ Engl J Med 353: $468-475$.

25. Yihua L, Yun J, Dongshen Z (2017) Coronary artery disease in premenopausal and postmenopausal women. Int Heart J 58: 095.

26. Kemp HG, Kronmal RA, Vliestra RE, Frye RL (1986) Seven year survival of patients with normal or near normal coronary arteriograms: A CASS registry study. J Am Coll Cardiol 7: 479-483.

27. Sharaf BL, Pepine CJ, Kerensky RA, Reis SE, Reichek N et al. (2001) Detailed angiographic analysis of women with suspected ischemic chest pain (pilo phase data from the NHLBI-sponsored women's ischemia syndrome evaluation (WISE) Study Angiographic Core Laboratory). Am J Cardiol 87: 937-941.

28. Dave TH, Wasir HS, Prabhakaran D, et al. (1991) Profile of coronary artery disease in Indian women: correlation of clinical, non-invasive and coronary angiographic findings. Indian Heart J 43: 25e29.

29. Kuruvilla S, Kramer CM (2013) Coronary microvascular dysfunction in women: An overview of diagnostic strategies. Expert Rev Cardiovasc Ther 11: 15151525

30. Johnson BD, Shaw LJ, Pepine CJ (2006) Persistent chest pain predicts cardiovascular events in women without obstructive coronary artery disease: Results from the NIH-NHLBI-sponsored women's ischemia syndrome evaluation (WISE) study. Eur Heart J 27: 1408-1415. 